\title{
Research on the application of teaching and Construction of the intelligent recording system
}

\author{
Bin Yuan \\ Information and Education Technology Center, \\ Qujing Normal University, Qujing Yunnan, 655011 \\ Yuanbin655011@126.com
}

\begin{abstract}
Keywords: Intelligent recording system; Excellent course; Video screen; Teaching application research
\end{abstract}

\begin{abstract}
Based on the curriculum construction of the universities and the education informationization construction needs, the intelligent recording system can be the student teachers' teaching, teaching, writing on the blackboard for infrared detection and tracking switching recording, production, editing and broadcasting one output instruction video for teachers, improve the timeliness of course making. By using the method of sampling questionnaire, the author investigates the present situation of the application and recording system of teachers in colleges and universities, and finds that the teachers are more inclined to choose the intelligent recording and broadcasting system with simple operation and fast application.
\end{abstract}

\section{Intelligent recording and broadcasting system}

\section{Intelligent Directed Broadcasting System.}

The intelligent director system is embedded in the video editing machine. It adopts the function of automatically switching the screen special effects, and the camera automatically switches the scene to realize the function of recording and recording video images in unattended state. The system displays the video images in many scene pictures (for example, Screen, blackboard picture, etc.) to complete the switch automatically, through the director system, the teacher self-completion of quality course recording work.

\section{Image tracking and positioning system.}

Image tracking and positioning system uses infrared sensor body temperature to trigger the camera tracking video, the system mainly by the teacher tracking system and student positioning system composed of two parts. Teacher tracking system uses an infrared sensor technology to automatically track the target of an advanced intelligent technology. The tracking system will intelligently recognize the position of the teacher standing on the podium. If the teacher goes down the podium and interacts with the students in the classroom, the system will control the camera to record the panorama video automatically. If the teacher takes the blackboard on the blackboard, the system will The teacher will use the mouse to click the computer lectures, the system will immediately switch to the recording screen to display the contents of the courseware, the teacher is in the picture-in-picture mode automatically recorded. In the whole process of tracking the video screen to switch smoothly during the smooth, courseware content screen capture and sample images clearly visible, to achieve high-definition shooting effect. Intelligent recording and recording system can automatically locate the students to speak and action recording, when students stand up to answer teacher questions or go to the lecture, the system will automatically switch to panoramic mode shooting, and the lens immediately to students and intelligent recording The student's close-up ${ }^{[1]}$. Therefore, the student positioning system to achieve a true sense of intelligent automation.

\section{Recording and broadcasting in the control system.}

The recording and broadcasting central control system is composed of the client central control panel, video tracking positioning control, recording and broadcasting streaming media server control and so on, which is the core subject of recording and broadcasting classroom construction. 
The client central control panel is a channel for the teachers to operate the self-service video recording. The system button on the panel can start and shut down the recording and playing system device directly. The automatic, manual, start, pause and teaching computer buttons are convenient for teachers to record and switch hands / Mode of the channel. Teachers automatically record the normal completion of the video compression automatically generated ASF streaming media format files stored in the system server root folder, the teacher can at any time after school recording the video stand-alone playback, file rename, copy and delete operations, which greatly improved Recording efficiency and effectiveness ${ }^{[2]}$.

\section{The Analysis of Intelligent Recording and Broadcasting System Assisted Classroom Teaching}

\section{Traditional teaching video disadvantages highlighted.}

According to traditional methods of teaching video recording, using artificial unattended camera, manual single point, after the export video filming late must also through electronic staff were artificial editorial, editing and special effects production, not only causing tension, still time-consuming, bother, virtually bring high cost to the subsequent editing, and produced through secondary processing to edit teaching video shot in a single picture content monotonous, lack of effective means to collect classroom interactive link video picture of the teachers and students. Fine courses cannot be achieved in terms of the overall structure of the teaching requirements, the whole class video recording process from beginning to end are almost all teachers of blackboard writing, blurring and features, along with the students listen to the teacher carefully in the lens is small, no lens and the change of JingBie, video content is monotonous, boring, the lack of aesthetic feeling and movement, and even a lot of shots to the back of students and the back of the head, the shooting area and the arrangement of the same in a normal classroom or multimedia classroom, due to the shooting area not specifically, daylighting effect is general, poor lighting conditions, classroom to record the scene of the noise didn't get effective control; In the process of the video recording, because some teachers are not used to face the camera and camera crew lectures, classroom atmosphere did not get effective relief, the class teacher when facing the camera and cameraman for the first time, because of nervousness and heart, in the face of student teaching discourse throughput is not clear, cannot be cast out of his lectures can and teaching skills, which affects the normal play to teachers' teaching level, students feel is just trying to help the teacher support, gather together, learning very poor ${ }^{[3]}$.

\section{The Advantages of Intelligent Recording and Recording System in Recording Excellent Course.}

In view of the above shortcomings of traditional video teaching, intelligent recording and broadcasting system in the course of teaching quality courses in a variety of ways, the screen flexible, interactive and friendly, and its automatic recording mode can be teachers and students in the gap between the characters close-up shooting, The video screen to switch to the computer desktop courseware and the classroom effect of the whole classroom, recording the quality of classroom teaching lectures is also the quality of the real audio site; Second, the intelligent recording and recording system recording dynamic video quality is very high, real-time smoothing Transition, seamless switching; Third, the system is simple and quick operation, the teacher in the class process only repeat the "record, pause, stop" button on the three to switch, you can complete the high quality of course recording, Save the recording costs, but also shorten the follow-up time to optimize the quality of courses, improve production efficiency ${ }^{[4]}$.

\section{Shot Switching of Intelligent Recording and Recording System in the Recording of Excellent Course.}

Intelligent recording and broadcasting system in the control panel is easy to understand, in the course of teaching quality recording, press the recording mode is divided into AUTO (automatic recording and broadcasting) and manual recording and broadcasting in two ways. Automatic recording mode does not require audio-visual staff to monitor the entire process of recording, the system will be based on teachers in the podium and classroom location and automatically track the positioning of dynamic automatic switching recording screen. Manual recording and broadcasting 
mode requires audio-visual administrators to complete the full-time teachers to manually operate the relevant equipment recording video course, we must monitor the progress of teaching teachers throughout the process, and through the backstage control system, manual manual operation platform interface, can dynamically switch Real-time screen to determine and timely adjust the recording node, and according to the actual situation to choose the best recording screen. As the selection criteria of the excellent courses are very strict and the competition is fierce, the teaching process not only reflects the complete course of the objective teaching, but also shows whether the teaching objectives of the teachers are clear and whether the teaching is clearly and clearly visible. The video recorded by the teacher must show high-quality classroom teaching resources and characteristics of the distinctive teaching level, therefore, excellent course recording on the lens selection and switching to a higher level of requirements, involving the screen, sound, editing, interactive and more A classroom teaching flash point, class teachers in the recording quality courses must have audio-visual administrator in the background control and control system interface through manual recording and broadcasting methods to switch to select the best recording screen, as far as possible the teaching process Wonderful, the most vivid, the most appealing scenes perfect show ${ }^{[5]}$.

\section{Intelligent recording and recording video recording lens selection}

\section{The teacher writing on the blackboard platform screen recording core priority switch lenses for curriculum. \\ If the focus of course record transfer to the class teacher, for example, in the demonstration of skills, the teacher in the class is mainly to explain and demonstrate that students only need to seriously take notes of the lectures, the teachers and the students have no interactive classroom teaching links, and teachers in the demonstration action when I positions relatively fixed. It can be used with the teacher as the center of the picture, giving priority to teaching staff on duty control system, recorded before switching to manual production mode, and recording screen switching to teachers as the center, auxiliary to the teachers in the personal demonstration, demonstrating high difficulty giving action figures feature ${ }^{[6]}$.}

\section{Listen to the teacher to students as the core focus priority change camera picture.}

If classroom teaching requires students to answer the question independently, in-class impromptu speech, flip the classroom teaching students to participate in activities such as group discussions. For example, group discussion, students demonstrate their learning achievements, to share their experience and so on, these links are used in the classroom students preferred mode of manual director, director staff to improvise, targeted recorded images to switch to teaching students, and intermittent give close feature, highlight students' enthusiasm to participate in class discussions, study hard.

\section{Teaching computer courseware to explain the screen priority switching lens.}

If teachers focus on video playback, picture presentation, appreciation courseware to answer questions during the teaching process. For example, the teacher of Ideological and moral and moral education needs to play the theme case videos, mechanical drawing lessons need to demonstrate drawing flow chart, then focus on teaching video recording is taught in the computer classroom lectures and video courses, must be video recording screen switches to teach computer desktop courseware, multimedia show the courseware content as the main rendering objects ${ }^{[7]}$.

\section{The construction of intelligent recording system and the matters needing attention}

\section{Intelligent taped classroom construction.}

In order to ensure the image quality excellent course video recording, recording to achieve the best effect, in the process of building the smart taped classroom should fully consider the classroom lighting effect, light intensity, and the platform seat arrangement, the classroom walls around the sound insulation device, speaker layout, camera placement and multimedia equipment, installation and debugging of projection screen. In the intelligent taped classroom location, should choose the 
more quiet and convenient for students and teaching building or experimental building, the walls of the classroom to do sound processing, involving the use of multimedia equipment, the window of the classroom to consider avoiding light treatment, the classroom lighting is not only to ensure the brightness required class school students, but also to avoid the projection for effect of reflective lamp light is too strong to. The classroom seating arrangement, according to the number of the students in the class size, determine the standard recording room number of installed seats, with good teaching atmosphere to achieve the excellent course video recording, the preset seats should not be too much, about 70 people in the general control routine. The seat should buy good quality, the student seat does not produce abnormal noise, so as not to affect the effect of the course of recording. The classroom should adopt the keynote stage vertical multifunctional multimedia platform, moderate height, to show a good image of teachers.

\section{The intelligent recording system notes.}

(1) In order to ensure the high quality courses recorded video image quality, the best recording effect, in the process of the construction of intelligent recorded the classroom should fully consider the classroom lighting effect, the light brightness, the platform and the seats arrangement, around the classroom wall sound insulation devices, general layout, the camera installation position and multimedia speakers equipment debugging, projection screen installation, etc. On intelligent taped classroom location, should choose relatively quiet and facilitate students in and out of the building or in the lab building, the classroom wall to do insulation treatment, involving the use of multimedia equipment, try to consider the classroom window light processing, the interior lighting lighting is needed to ensure that students in the class brightness, and avoid the curtain projection of reflective effect as a result of light is too strong. Inside the classroom seating arrangement, according to the number of students in class size, determine how much seat installation standards recorded classroom, to achieve the fine course video recording has good teaching atmosphere, the default seat shoulds not be too much, general control in conventional about 70 people. Seat should choose and buy quality is better, the student table does not produce abnormal noise, lest affect course recording effect. The speaker's appropriate USES vertical multi-functional multimedia platform, medium height, to show the image of good teacher ${ }^{[8]}$.

(2) Skilled teachers recorded system operation specification, and sufficient preparation of curriculum content, avoid lecture informative errors or nonstandard action of teaching instrument and manner, because part of the teacher in class at ordinary times did not pay attention, some conceptions is more noticeable, effective solution is: be responsible for the recorded assistant teacher in advance and teaching of teachers and students communicate with the class in class, in the course to be recorded pre - recorded listening evaluation, the teacher keep teaching emphasized the lecture itself dignified appearance, dress neatly, articulate, blackboard writing clear ${ }^{[9]}$.

\section{Teaching application research}

Intelligent recorded system teaching application research adopts the method of sampling survey, the author in October 2016 to participate in the China education and research computer network CERNET 23rd annual meeting of the academic, issuing questionnaires to attend the meeting of university teachers, survey data show that $70.8 \%$ of schools have installed copy and play system, $12.5 \%$ of schools has not been equipped with recorded system, in addition, there are $16.7 \%$ of the teachers don't know whether your school has a copy and play system; Asked about expectations with what types of copy and play system to achieve the ideal teaching effect, feedback the results showed that $55.2 \%$ of the teachers choose automatic intelligent recorded system, $28.3 \%$ of the teachers expect to use portable mobile copy and play system, $16.5 \%$ of the teachers to choose professional virtual studio. Therefore, college teachers tend to be more intelligent copy and play system, because intelligent recorded system operation is simple, fast, easy to learn and teachers control $^{[10]}$. 


\section{Conclusion}

Intelligent recorded system's application in video recording work excellent courses in colleges and universities teaching plays a vital role, universities introduced into intelligent recorded system, has carried on the recording to declare all kinds of high quality courses at all levels, achieve the expected effect, effectively promote the fine course construction of universities.

\section{Acknowledgement}

This paper is supported by the Science Research Foundation of Qujing Normal University (2012QN025)

\section{References}

[1] Lin Liangliang.Design of recording and broadcasting system based on teaching application in colleges and universities [J], Digital Education, 2015 (4): 26-27.

[2] Li Zhigang.High-definition automatic recording and broadcasting system construction [J], Nanjing Radio and Television University, 2015 (4): 43-44.

[3] Jing Dejiang.Analysis of recording and broadcasting system [J], Computer Software and Application, 2012 (9): 33-34.

[4] ZHANG Fei-fei.Application of intelligent recording and broadcasting system in mobile learning of colleges and universities [J], China Education Informatization, 2014 (6): 25-27.

[5] Li Juan.Construction and Application of Multimedia Automatic Recording and Recording Classroom [J], Computer Knowledge and Technology, 2012 (15): 26-30.

[6] YAN Lei, QI Bing.Discussion on the Construction of Comprehensive Course Recording and Broadcasting System in Colleges and Universities [J], China Off-Campus Education, 2013 (7): 32-35.

[7] Zhu Zhen-zhong. Full HD recording and broadcasting system to support teachers and students "teaching" and "learning" [J], China Modern Education Equipment, 2015 (16): 9-15.

[8] Feng Li-dan. The construction of automatic intelligent recorded system [J], " Guangxi Journal of Light Industry C: Professional and higher education, 2015 (23) : 182-183.

[9] Yang Yuyu, Nie Yong. Application of recording system in the domestic teaching in the analysis of [J], Chinese education information, 2015 (22): 36-38.

[10] Zheng Shuhong. Application of [J] multimedia recording and broadcasting system in the college course construction, information and computer (THEORY EDITION), 2012 (7): 39-41. 